\title{
Screening of Micro Flora found in Soil Samples Surrounding the Paper Mill in North-Western Region of Uttar Pradesh, India
}

\author{
Nisha Dhillon*, Shalu Choudhary, Surbhi Chaudhary, \\ Megha Singh, Sonam Arya and Lalit Kumar
}

Department of Biosciences, College of Applied Education and Health Sciences, Meerut, Uttar Pradesh, India

*Corresponding author

\section{A B S T R A C T}

\section{Keywords}

Bacteria,

Bioremediation,

Effluents,

Environmental

pollution, Soil

sample

Article Info

Accepted:

12 February 2019

Available Online:

10 March 2019
Pulp and paper industries are considered as one of the major polluters of the environment all over the world. These industries are the fifth largest contributor to water pollution. Pulping process, used for paper manufacturing leads to release of toxic chemicals or effluents into the environment and pollute water, air and soil therefore it is a major threat to ecosystem. A number of microbes have been found in the nearby soil of paper mill that are useful in the breakdown of environmental pollutants. Our approach was to demonstrate the presence of bacteria that are useful in the process of bioremediation. The indigenous bacterial species found in the soil sample nearby paper mill were Pseudomonas, Bacillus, Klebsiella, Proteus, Alcaligenes and Streptococcus out of which Pseudomonas, Bacillus and Alcaligenes have been found to be very useful in bioremediation process. Serial dilution, sub-culture, staining and biochemical testing were performed for the identification of bacterial species.

\section{Introduction}

Industrialization and globalization has lead to exploitation and pollution of natural resources for decades. World demand for paper has grown rapidly and was around 5-6\% per year. The paper mills have a larger investment and provide employment to 2 lakh people. It is estimated that the capacity of the mills increased from 8.3 million tonnes in 2010 to 14 million tonnes in 2020. In India, 70\% production of paper is from hardwood and bamboo fiber, agro-waste and remaining 30\% is from recycled material (Jeenathunisa et al., 2017). The paper industry is the largest industry in India which is disturbing the ecological balance of the environment by discharging a wide variety of waste water in their surroundings (Singh, 2015).

Wastewater is generated at different levels of paper manufacturing method which comprises of two main processes- pulping and bleaching. In the pulping process, paper pulp 
is manufactured from the cellulose fibers contained in wood. The effluent formed at this stage contains lignin, hemicellulose, resins, acids, phenols, etc. which impart dark brown color to wastewater. Effluents from bleaching process contain chlorinated organic compounds, and Inorganic compounds include heavy metals like manganese, lead, cadmium, chromium, iron, copper, mercury, etc. and gases such as nitrogen oxide, phosphorus oxide, hydrogen sulphide, etc. These compounds act as major sources of pollution not just because they are toxic above a relatively low concentration but also because they are persistent remaining in the environment for long even after the removal of source of contamination. Number of microorganisms including bacteria, fungi and actinomycetes has been implicated to degrade the xenobiotic compounds present in pulp and paper mill effluent. (Hossain and Ismail, 2015).

In the entire paper pulp plant, bleaching process discharges the highest amount of pollutants into the water streams and nearby soil surroundings. Various studies have claimed the detrimental effects of the effluents coming out of pulp and paper mills on living organisms, water bodies and soil receiving these pollutants.

A study in 1996 reported health impacts such as diarrhea, vomiting, headaches, nausea and eye irritation on children and workers due to the pulp and paper mill wastewater discharged to environment (Singh, 2011). These effluents are also found to exhibit mutagenic effect and adversely affecting biodiversity.

The wastewater generated in bleaching process has a high concentration of sodium and a high sodium adsorption ratio which leads to increased sodium content in the soil, thus degrading the soil's quality. The disposal of paper mill effluent showed significant $(\mathrm{P}<0.05)$ changes in soil characteristics. The soil parameters namely: moisture content $(10.19 \%)$ and WHC (11.48\%) were decreased, while $\mathrm{pH}(2.75 \%)$, IC (126.08\%), Chlorine ion (46.35\%), OE (38.70\%), Sodium ion (66.44\%), Potassium ion (24.03\%), Calcium ion $(72.16 \%)$, Magnesium ion (144.97\%), TKN (66.73\%), Phosphate ion (238.83\%), Sulphate ion (23.78\%), Cadmium (1451.47\%), Chromium (2082.85\%), Copper (115.47\%), Iron (107.81\%), Lead (496.5\%) and Zinc $(138.68 \%)$ of the soil were increased after disposal of paper mill effluent in comparison to control soil (Kumar et al., 2015).

Among different heavy metals discharged from paper mill, chromium showed maximum contamination and iron showed minimum contamination (Kumar et al., 2015). These studies show that paper mill effluents significantly affect characteristics or nature of soil in the vicinity of effluent discharge. Therefore, it is obligatory to treat the effluents before their discharge into environment.

Several methods have been employed to remove color from pulp and paper mill effluents. These can be categorized into chemical, physical and biological methods. Chlorinated phenolic compounds and adsorbable organic halides (AOX) can be efficiently reduced by adsorption, ozonation and membrane filtration techniques (Pokhrel and Viraraghavan, 2004) in almost all pulp and paper industry full scale applications, anaerobic treatment is followed by aerobic post treatment. The suitability and the cost of the anaerobic-aerobic and aerobic treatment systems are largely affected by a variety of mill specific factor (Rintala et al., 1994).

The biological colour removal process uses several classes of microorganisms-bacteria, algae and fungi to degrade the polymeric 
lignin derived chromophoric material (Sharma et al., 2014). Other materials are degraded slowly, accumulate in the environment and occasionally exhibit toxicity (Singh, 2011). Thus, our objective was to isolate and identify indigenous bacterial species found in soil near paper mill area that could help efficiently and economically in the treatment of paper mill effluents.

\section{Materials and Methods}

Various materials and types of media were employed. The glass wares used were Erlenmeyer flasks $(250 \mathrm{ml}$ and $500 \mathrm{ml})$, beakers, Petri dishes, glass rods, test tubes, glass slides and dropper. The media that were used included nutrient agar media (NAM), Mac Conkey agar media, Blood agar media, Simmon's citrate agar media and Urea agar media. The broth included tryptone broth, MR-VP broth, and Hugh and Leifson's OF basal media. Different equipments were used like autoclave, bunsen burner, laminar air flow (LAF) cabinet, inoculating loop, micropipettes, test tube stand, etc.

The soil sample was collected from vicinity of paper mill from north-western region of Uttar Pradesh. The samples were collected in 500 ml capacity sterile BOD Bottles. The collected samples were brought to the laboratory and analyzed for various isolation of microflora and its physico-chemical. The sample was taken from a few centimeters deep and then serially diluted in laboratory. NAM plates were prepared and sample was spread on them. Overnight incubation was given at $37^{\circ} \mathrm{C}$.

Sub-culture: The different colonies obtained from the overnight culture were streaked onto NAM plates for the isolation of pure bacterial colonies. Incubation was given at $37^{\circ} \mathrm{C}$.

Morphological characterization: Morphology was identified by Gram's staining. Smears were prepared and stained according to the Gram's staining procedure to differentiate between Gram+ve and Gram-ve bacteria (Gram. 1884). Shapes were also examined. The differences in staining responses to the Gram stain can be related to chemical and physical differences in their cell walls. The morphology was also examined on NAM. The colonies occur in different sizes and shape like circular, irregular, rhizoid or filamentous.

Biochemical characterization: Various biochemical tests were performed to identify different species of bacteria. These tests are as follows: indole test, methyl red test, VogesProskaeur test, oxidase test, catalase test, urease test, oxidative fermentation test, etc.

Various confirmatory media were also prepared and streaked with bacteria to identify whether they are hemolytic or nonhemolytic and lactose fermenter. For testing hemolysis, blood agar was used and for testing lactose fermentation, MacConkey agar was used.

\section{Results and Discussion}

Isolation of bacterial colonies was done on NAM media. After overnight incubation of dilution plates $10^{-4}, 10^{-5}, 10^{-6}$ and $10^{-7}$, the following bacterial colonies were observed as shown in figure 1.

On sub-culturing, pure bacterial colonies were isolated which were differentiated on the basis of pigmentation and morphological characteristics. Colonies of different colors (creamy, white, transparent and green), shapes (rhizoid, irregular edges) and size were seen as shown in figure 2 .

After sub-culturing, biochemical analysis of the pure bacterial colonies was done. Various biochemical tests were performed and differential media employed to determine the 
kind of species. Mannitol Salt Agar (MSA) media was prepared and colonies were cultured but only Streptococcus showed minimal growth; MacConkey Agar media was prepared to check the presence of gram negative and lactose fermenting species, on which Pseudomonas, Klebsiella, Alcaligenes and Bacillus showed growth; Bacillus and Streptococcus showed pink coloured colonies which means they are capable of fermenting lactose, Pseudomonas and Klebsiella showed growth on Blood Agar media but these were non-hemolytic in nature whereas Bacillus was found to be hemolytic in nature.

The biochemical tests performed included IMViC test, oxidase test, catalase test and urease activity test, the results of which are given in the table 1.
Proteus shows positive result in Indole production, MR reaction, VP reaction, Urease activity and catalase activity. Streptococcus shows positive result in Gram Staining, Lactose Fermentation and Indole Production. Klebsiella shows positive result in Citrate activity, Urease activity and Catalase activity. Bacillus mycoides shows positive result in Gram Staining, Lactose Fermentation, VP reaction, Urease activity and Catalase activity. Pseudomonas putida shows positive result in Citrate activity, Urease activity, Catalase activity and Oxidase activity. Pseudomonas aeruginosa shows positive result in Citrate activity, Catalase activity and Oxidase activity. Alcaligenes shows positive result in Catalase activity and Oxidase activity. Table 1 shows that Proteus and Bacillus mycoides gives maximum positive result while performing biochemical analysis.

Table.1 Biochemical analysis of bacterial colony obtained from soil nearby paper mill industry in Northern Region

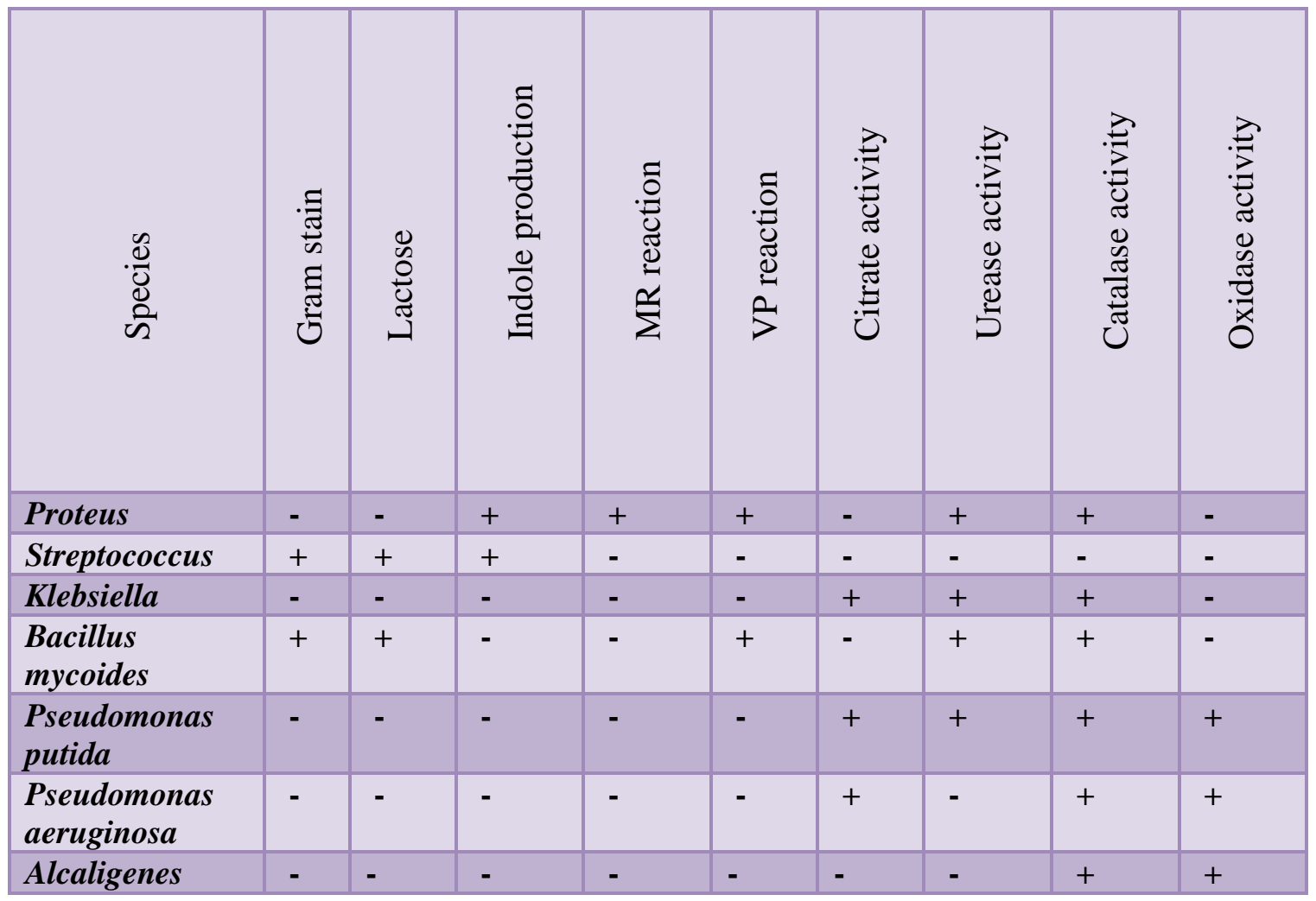


Fig.1 Bacterial colonies as observed after serial dilution of soil sample and overnight incubation

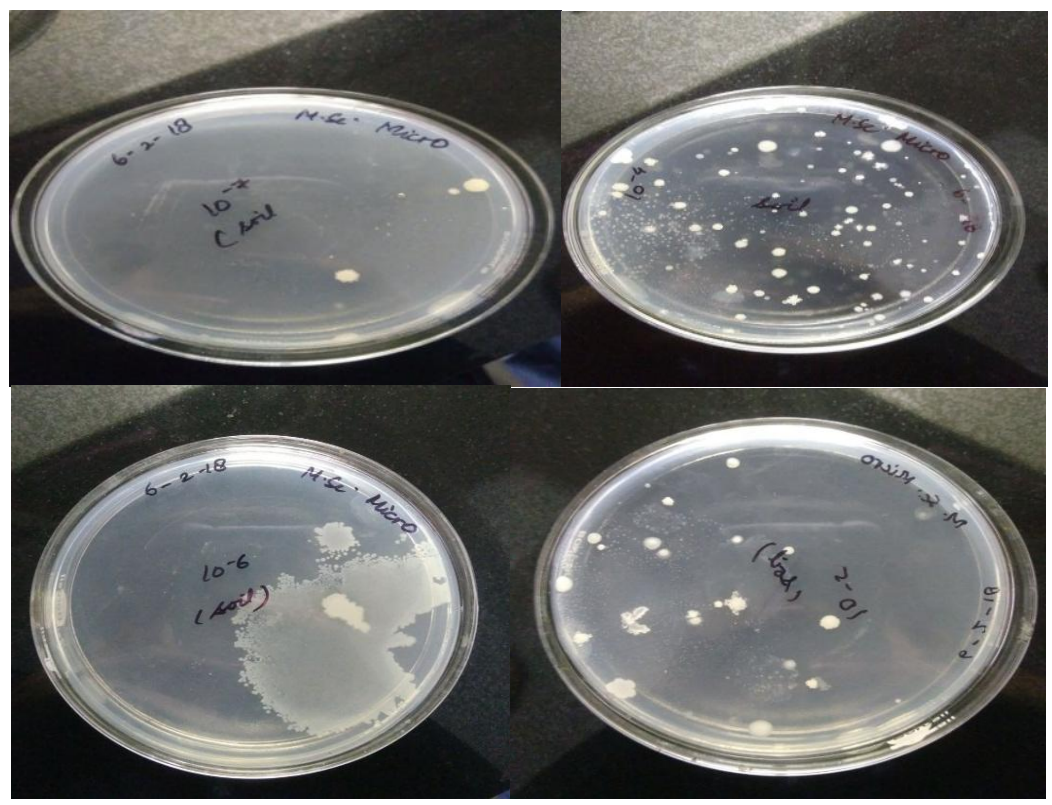

Fig.2 Colonies observed after sub-culturing of overnight incubated plates
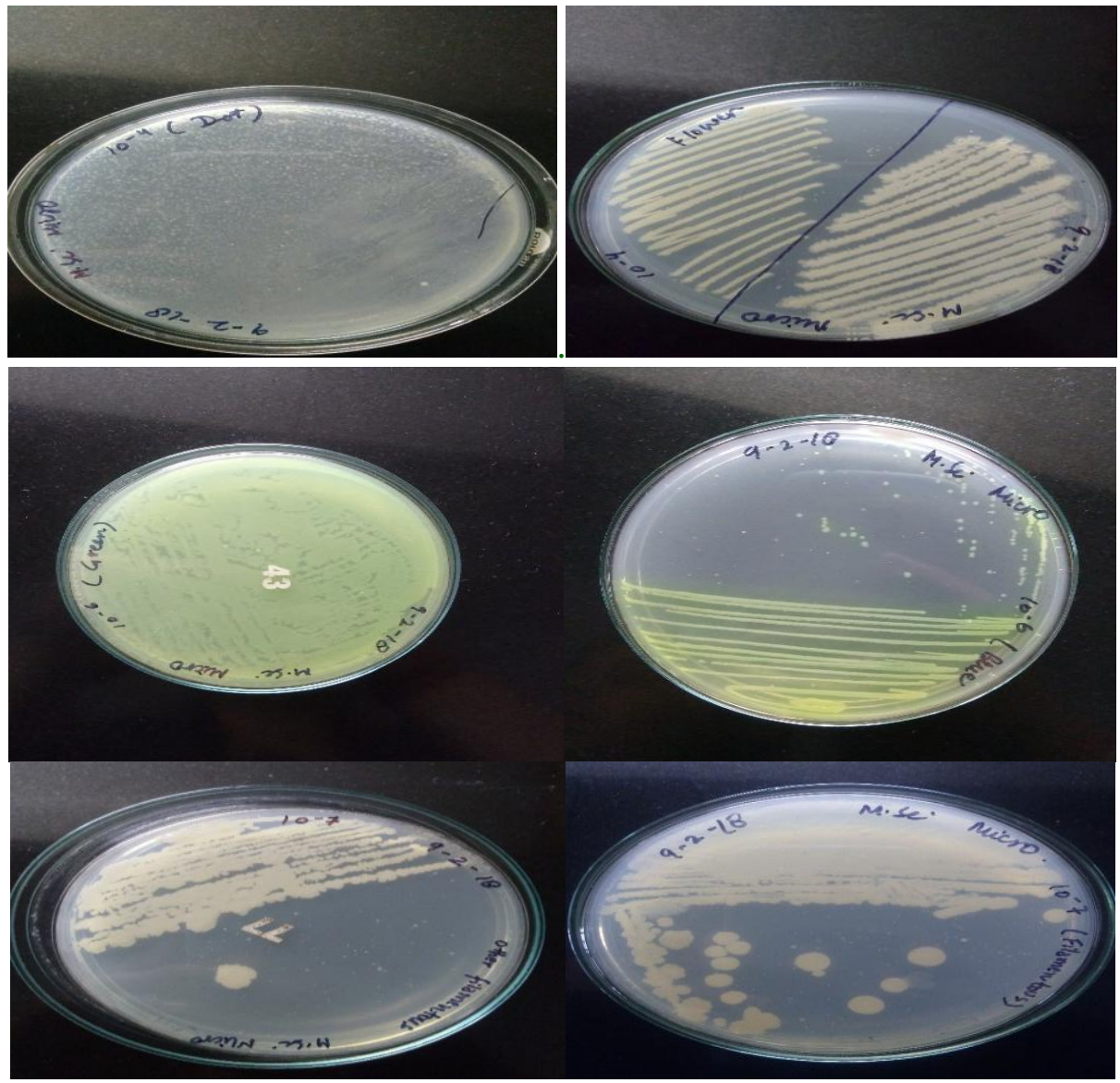
Based on the results of the above conducted experiment it can be inferred that bacterial species such as Proteus and Bacillus mycoides show maximum prevalence near paper mill industry. This shows that are capable of biodegradation of paper mill waste are present near the site of pulp and paper mill indigenously. Further research could be done to study the ability of micro organisms which are likely to provide economically biodegradable processes for treating waste from paper industries. These species could be efficiently utilized in the transformation of harmful paper mill waste into compounds that are no longer harmful or less detrimental to living organisms and their surrounding environment.

\section{Acknowledgment}

We are highly thankful to College of Applied Education and Health Sciences for providing the laboratory facilities for doing our work.

\section{References}

Chupal, Y., Kumar, V. and Thakur, I. S. 2005. Biodegradation and decolourization of pulp and paper mill effluent by anaerobic and aerobic microorganisms in a sequential bioreactor. Wor Jour of Micr an Biot. Vol (21). 1439.

Ghoreishi S.M. and Haghighi M.R., 2007. Chromophores Removal in Pulp and Paper Mill Effluent via Hydrogenation-Biological Batch Reactors. Chem Engi Jour Vol127.61.

Hossain K and Ismail N, 2015. Bioremediation and Detoxification of Pulp and Paper Mill Effluent. Rese jour of EnviToxi, Vol9.113.

Jeenathunisa. N, Jeyabharathi. S and Arthi. J, 2017.Bioremediation of Paper and Pulp Industrial Effluent Using Bacterial Isolates. Inte Jou for Rese in App Sci \& Engi Tech. Vol 5.692.

Kumar V, Singh J, Kumar S ,Chopra A.K and Thakur R.K, 2015. Effects of pulp and paper mill effluent disposal on soil characteristics in the vicinity of Uttaranchal pulp and paper mill, Haridwar (Uttarakhand), India. Inte Jour of Agri Sci Rese Vol.4.117.

Maheshwari R, Rani B, Saxena A, Prasad M and Singh U , 2012. Analysis of effluents from recycled paper Industry. Jour of adv sci res. 3(1).82.

Murugesan K, 2003. Bioremediation of paper and pulp mill effluents. Ind Jour of Exp Bio (41). 1243.

Pokhrel, D. and Viraraghavan T, 2004. Treatment of pulp and paper mill wastewater. Sci of the tot envi. Vol (333).37.

Rintala, J. A. and Puhakka. 1994. Anaerobic treatment in pulp and paper mill waste management. Bio Tech Vol (47).1.

Singh, A. 2011. Microbial degradation studies in pulp and paper industries. Jour of Jay Vid Wom Uni.4(6).

Singh, S. 2015. Study of waste water effluent characteristics generated from paper industries. Jour of Bas and Appl Engg Rese Vol 2.1505.

http://scialert.net volume 9 (3).

www.suezwaterhandbook.com

Sharma, R., Chandra, S., Singh, A. and Singh, K. 2014. Degradation of pulp and paper mill effluents. IIOAB Jour 5(3): 6-12.

\section{How to cite this article:}

Nisha Dhillon, Shalu Choudhary, Surbhi Chaudhary, Megha Singh, Sonam Arya and Lalit Kumar 2019. Screening of Micro Flora found in Soil Samples Surrounding the Paper Mill in North-Western Region of Uttar Pradesh, India. Int.J.Curr.Microbiol.App.Sci. 8(03): 1633-1638. doi: https://doi.org/10.20546/ijcmas.2019.803.190 